\title{
A CRÍTICA DE HANNAH ARENDT A NOÇÃO DE PROGRESSO
}

Mário Sérgio Vaz $^{\underline{1}}$

RESUMO: Trata-se de apresentar a crítica de Hannah Arendt (1906-1975) a noção de progresso a partir de seu ensaio Sobre a violência (1969). A saber, Arendt indica no final do primeiro capítulo de seu livro Sobre a violência, que a ideia de progresso passou a ser vista dentro do movimento da Nova Esquerda [New Left] como um refúgio confortável com relação à realidade, dado que poderia fornecer respostas para a pergunta: o que faremos agora? $\mathrm{E}$ a resposta seria apostar na ação violenta como o elemento necessário para modificar o curso político. Todavia, Arendt observa ainda que o conceito de progresso, dentro de qualquer teoria da história de vertente teleológica, está em flagrante contradição com o século XX, dados os eventos totalmente inauditos que nele se passaram. Não obstante, trata-se de pensar, de acordo com a autora alemã, o progresso nos termos de uma "fé cega", que encontrou aceitação universal devido aos avanços das ciências naturais e a crença subjacente de que estas seriam ciências "universais", responsáveis pela tarefa hercúlea de explorar ilimitadamente o espaço e de "elevar a estatura humana."

Palavras-chave: Progresso; Ciência;Violência.

\section{THE CRITIQUE OF HANNAH ARENDT THE NOTION OF PROGRESS}

ABSTRACT: We try to show the Hannah Arendt's criticism to the notion of progress from his essay On Violence (1969). Arendt points out, in the end of the first part of his book On Violence, that the idea of progress came to be seen within the New Left movement as a comfortable refuge from reality, since it could provide answers to the question: what are we going to do now? And the answer would be to bet on violent action as the necessary element to change the political course. However, Arendt further notes that the concept of progress, within any theory of teleological history, is in flagrant contradiction with the twentieth century, given the totally unprecedented events that have taken place in it. Nevertheless, it is a matter of thinking, according to the German author, of progress in terms of a "blind faith", which has found universal acceptance because of the advances of the natural sciences and the underlying belief that these would be "universal" responsible for the herculean task of unlimited exploration of space and "elevating human stature."

Keywords: Progress; Science; Violence.

Pretende-se apresentar uma breve reflexão sobre alguns aspectos fundamentais da posição de Hannah Arendt frente a noção de progresso. Para tanto, assume-se aqui como referencial teórico o primeiro capítulo de Sobre a violência (1969), onde a autora alemã expõe seu diagnóstico crítico com relação a este tema e o seu vínculo com a violência. Inicialmente, 
Arendt realiza uma breve recapitulação do sentido que o conceito de progresso [progress] assumiu dentro de nossa história recente, trazendo que para os homens do século XVII, este termo significava acúmulo de conhecimento e, mais tarde, no século XVIII, passou a ser entendido como uma educação da humanidade, cujo fim coincidiria com a maioridade de todos os homens. Porém, de acordo com Hannah Arendt, este conceito tornou-se um dos artigos mais sérios e complexos de nosso tempo. Isso porque, a partir do século XIX, a noção de progresso encontrou sua raison d'être justamente na esteira do surpreendente desenvolvimento das ciências naturais, que para Arendt, desde o seu nascimento têm sido exemplares na tarefa de romper com os limites e finitude de nossa morada - a Terra. Consequentemente, ao explorar o universo infinito e dissolver a fronteira entre aquilo que era dado pela natureza e aquilo que era dado pela cultura - o mundo - as ciências naturais desencadearam processos que naturalmente não ocorreriam aqui, mas apenas no Sol. ${ }^{2}$ Destarte, o progresso científico carrega consigo preocupações e consequências de ordem política, tanto no que se refere aos seus feitos, quanto aos seus efeitos.

Sendo assim, de acordo com Hannah Arendt, o progresso tecnológico e científico, uma vez que não coincidem devidamente com o progresso da humanidade "não mais serve como o padrão por meio do qual avaliamos os processos de mudança desastrosamente rápidos que desencadeamos " (ARENDT, 2001, p. 39). Segundo a autora, isso é perceptivelmente sentido na medida em que marchar para o futuro - algo que de todo não nos é possível evitar exprime o processo de contínua transposição de barreiras naturais que, em seu lastro, carrega a possibilidade cada vez mais real de disseminar o fim da humanidade por meio de uma guerra nuclear.

Trata-se aqui de perceber como a ciência e a política, no que diz respeito à relação com o mundo, adotam caminhos opostos. De acordo com a reflexão de Arendt em seu ensaio A Conquista do Espaço, isso se deve ao fato de que: "A glória da ciência moderna foi ter sido ela capaz de emancipar-se completamente de todas as semelhantes preocupações antropocêntricas" (ARENDT, 2003, p. 327). Com efeito, ciência e política não mais falam a mesma linguagem. Problema este devido não apenas à amoralidade científica ou à difundida ignorância pública dos cientistas, mas pelo fato de o método científico por si mesmo encabeçar perigosos precedentes para a vida pública. Enquanto que a política diz respeito ao

\footnotetext{
${ }^{1}$ Graduado em Filosofia pela Universidade Estadual do Centro-Oeste (UNICENTRO). Mestrando em Filosofia pela UNIOESTE, linha de ética e filosofia política 2018 - 2020

${ }^{2}$ A respeito desta discussão ver seu ensaio "A Conquista do Espaço" presente no livro Entre o Passado e o Futuro.
} 
estar junto no mundo e demanda uma responsabilidade de cada cidadão para com este espaço da aparência, por outro lado, para Arendt, as ciências naturais - exemplarmente a física nuclear - que através das explosões atômicas inauguraram o mundo moderno, desembaraçadamente não compartilham deste mesmo amor mundi.

Para Arendt, a crença no ideal de progresso ilimitado é tanto irracional quanto impraticável, na medida em que ocorre um descompasso entre o atual estágio de desenvolvimento das ciências naturais e as chamadas ciências das humanidades. Noutros termos, ocorre um problema ao se projetar para as ciências do espírito - e esta impossibilidade também se aplica ao campo da política - a mesma atitude científica e o mesmo desejo de objetividade presente nas ciências naturais. A razão disso, para Arendt, é que o padrão de cientificidade repousa em uma "extinção de qualquer aspecto antropomórfico do mundo" em favor dos constantes experimentos que são realizados a partir de modelos e padrões previamente estabelecidos.

Especificamente para o âmbito da política, a ciência, ao arrogar para si o papel de reguladora dos assuntos humanos, ambiciona prever de maneira confiável os resultados das ações humanas. Neste ímpeto, reduz, toda ação - e com ela sua espontaneidade e imprevisibilidade - em projeções de condutas e comportamentos.

A esta prerrogativa da ciência, Arendt aponta que:

\footnotetext{
Calculam as consequências de certas suposições hipoteticamente assumidas, sem contudo, serem capazes de testar suas hipóteses contra as ocorrências reais. A falha lógica nestas construções hipotéticas dos eventos futuros é sempre a mesma: aquilo que primeiro aparece como uma hipótese - [...] torna-se imediatamente , em geral, após uns poucos parágrafos, um "fato" (ARENDT, 2001, p. 14).
}

Vê-se que para Arendt, não há como projetar ou criar simulações do resultado das ações humanas porque elas são par excellence imprevisíveis. Toda ação é distinta, e por ser dotada de um caráter de novidade, nunca pode ter seu fim plenamente previsto. Nestes termos, Arendt critica a suposta necessidade das ciências do espírito e sociais de imitarem o modus operandi das ciências naturais calcadas no paradigma de que só é possível conhecer e acessar o "mundo real" por meio de experimentos.

O entrelaçamento entre a confiança num progresso ilimitado e a ciência faz com que toda a pluralidade humana se reduza ao estatuto de simples "subcategoria" diante do éthos científico, dado a maneira impessoal de lidar com o planeta Terra destas ciências que partem do princípio de que o sensível - a aparência - pode ser reduzido à linguagem matemática, em 
gráficos e planilhas que não precisam ser expressos em termos da linguagem ordinária nem dependem do consenso para serem assumidas. Para a autora, esta instanciação resultou na divisa entre uma certa verdade tipicamente científica (matemática) - não consensual e indubitável que só diz respeito ao cientista isolado do mundo - e o nosso senso comum [common sense].

Desta forma, pode-se dizer com o professor Rodrigo Ribeiro Alves Neto no seu artigo "Tecnologia, política e modernidade" que:

\begin{abstract}
A racionalidade científica moderna rompeu com a experiência ordinária e concreta do mundo humano, desvencilhando-se do plano da percepção e da linguagem e, consequentemente, do senso comum e mundo ordinário dos sentidos. A ciência constrói o algoritmo e fala através dos algoritmos ou de uma combinatória matemática (ALVES NETO, CAD. DE FILOSOFIA ALEMÃ, No 28, p. 153).
\end{abstract}

Ou seja, na perspectiva do fazer científico, nada do que possamos observar através de nossos sentidos - enquanto indivíduos pertencentes do mundo - forneceria algo de relevante. Os olhos do cientista permanecem totalmente desvinculados de nossas preocupações terrenas de uma maneira análoga ao filósofo que contemplou o sol divino e não foi capaz de transmitir aos seus companheiros, numa linguagem compartilhada, o sentido e o conteúdo de sua visão. Ora, na tentativa de transferir esta lógica para os assuntos humanos, é tentador querer tratar dos assuntos políticos por meio de fórmulas, hipóteses de trabalho e acreditar que é possível alcançar um pleno entendimento a respeito desses "eventos hipotéticos", i.e, das ações humanas e do seu fluxo, daquilo que virá depois. Segundo Arendt (2001, p. 15) ocorre uma falha lógica nessa construção hipotética acerca dos eventos futuros pois aquilo que primeiro aparece como hipótese dentro de uma fórmula, torna-se em geral, após algumas linhas, em um "fato." Isso não é "científico" finaliza Arendt, mas "pseudocientífico", pois toda e qualquer ação humana: "para o melhor ou para o pior, todo acidente, destroem necessariamente todo o modelo em cuja estrutura move-se a previsão, e no qual ela encontra a sua evidência " (ARENDT, 2001, p. 16).

Para os adeptos desta perigosa superstição, ${ }^{3}$ o progresso só faria sentido se detivéssemos pleno controle acerca das ações humanas, i.e se elas fossem manipuláveis como eventos físicos. Mas este não é o caso segundo Hannah Arendt, que concebe a história como sendo composta de eventos singulares, acontecimentos únicos que se constituem em rupturas.

\footnotetext{
${ }^{3}$ Nas palavras de Arendt: “O progresso, por certo, é um dos artigos mais sérios e complexos encontrados no mercado de superstições de nosso tempo" (Cf. ARENDT, 2001, p. 29)
} 
Não há para a autora, um grande livro da história único e dialeticamente inteligível, mas sim, um grande livro sobre as múltiplas e diversas histórias das ações humanas. Bem verdade, a ciência torna-se, pois, como acusavam sobriamente os movimentos estudantis e as rebeliões dentro do contexto norte americano, um reduto para as tecnologias de guerra e para produção de simples objetos de consumo, e somente em um mundo onde ninguém mais agisse e nada de importante acontecesse poderia realizar o sonho dos futorologistas.

É nesse sentido preciso que Arendt afirma: "Não preciso acrescentar que todas as nossas experiências neste século, que sempre nos confrontou com o totalmente inesperado, estão flagrantes contradição com estas noções e doutrinas [...]” (ARENDT, 2001, p. 28). De acordo com Arendt, qualquer concepção ideal de progresso foi simplesmente dissolvida devido a ascensão do totalitarismo nazista e soviético. E num sentido ainda mais específico, mesmo a rebelião estudantil inspirada quase em sua totalidade em questões morais é um exemplo destes eventos inesperados. De acordo com Arendt (2007, p. 16), querer ordenar a ordem dos assuntos humanos e os eventos inesperados e imprevistos a partir de padrões filosóficos e científicos é condená-los à irrelevância, pois tais teorias operam em cima de teorias que retiram suas evidências de hipóteses aparentemente consistentes, mas que, impossibilitam a compreensão e o discernimento devido daquilo que se passa.

Para a autora, se por um lado a Nova Esquerda logrou êxito ao perceber este descompasso, por outro lado, buscou refúgio em uma inconsistente visão de história tida aos moldes de um processo cronológico contínuo - onde a violência em forma de guerra e revolução poderia ser a única interrupção possível na continuidade temporal, a única maneira de tomar as rédeas da marcha para o futuro. Assim, pode-se dizer que o progresso ainda faria sentido enquanto tido somente enquanto um retiro especulativo onde ainda é possível acreditar em um movimento dialético dos acontecimentos. Contudo, afirma Arendt: "Se isto fosse verdadeiro, se apenas a prática da violência fosse capaz de interromper processos automáticos na esfera dos assuntos humanos, os apologistas da violência teriam ganho um ponto importante" (ARENDT, 2001, p. 30).

E como fora discutido, este não é o caso para a autora, que depois de analisar os acontecimentos do século XX, observou que a ideia hegeliana de que o espírito absoluto e as ideias tenham vontade própria e conduzem a história para uma direção predetermina não faz mais sentido. São antes as ações humanas, suas palavras e decisões que constituem e põe em movimento a esfera da política, que desviam ou bloqueiam seus eventos, somente por meio das ações (estas que não podem ter um fim predeterminado) que se interrompem os processos 
históricos, apenas por meio da promessa que se orienta o futuro e apenas por meio do perdão que acessamos o passado.

\section{REFERÊNCIAS}

ALVES NETO, R. R. “Tecnologia, política e modernidade”. In: Cadernos de Ética e Filosofia Política, $N^{\circ} 28$.

ARENDT, Hannah. Sobre a violência: tradução de André Duarte. - Rio de Janeiro: Relume Dumará, 2001.

Perspectiva, 2007.

Entre o Passado e o Futuro. [Tradução Mauro W. Barbosa]. São Paulo:

Perspectiva, 2004.

Crises da república. $2^{a}$. ed. Trad. José Volkmann. São Paulo:

CORREIA, Adriano. Hannah Arendt e a modernidade: política, economia e a disputa por uma fronteira. $-1^{\mathrm{a}}$ ed. - Rio de Janeiro: Forense universitária, 2014

DUARTE, André. "Poder e violência no pensamento de Hannah Arendt. In: Sobre a violência, 1994, pp. 81-94. 